\title{
Better = faster? Explaining citizens' desired speed of European integration
}

\author{
Thomas Malang \\ Department of Politics and Public Administration, Universität Konstanz, Konstanz, Germany
}

\begin{abstract}
Is the public EU membership evaluation similar to the support for further integration or different? Starting from the assumption that the EU is - compared to stable nation states - still a 'polity in the making', the paper answers the question which factors can explain the desired speed of integration. I first hypothesise that the standard economic, political and cultural explanations have the same effect for the (prospective) desired speed of integration than they have for the (retrospective) membership evaluation analysed in previous studies. Additionally, I develop two temporal explanations specifically for the explanation of future support. The results on the basis of Eurobarometerdata from 2008 suggest that the canonical economic and political theories work only for the explanation of the membership evaluation and not for the desired speed.
\end{abstract}

\section{Introduction}

The future of the European Union hinges more than ever on the popular support by Europeans. The core question of the burgeoning literature on public attitudes remains surprisingly stable: 'What explains variation in attitudes toward European integration' (Hobolt and de Vries 2016, 2). In this paper, I challenge the one-dimensional approach of general approval or disapproval of the European project. I empirically observe and theoretically argue that there is a difference between the general evaluation of the $\mathrm{EU}$ and the public opinion towards more and faster future integration. In the light of the current events, especially the referendums on disintegration, it is apparent that the results speak not only to a small community of rather technical-oriented public opinion scholars but that the analysis of the public sentiments about future integration deem to be relevant for many EU scholars and policy-makers alike.

The core presumption is the double nature of the evaluation of European integration. As Hacking remarks, '[m]ost words ending in "tion" are ambiguous between process and product, between the way one gets there, and the result' (Hacking 1999, 36). I follow that European integration (Ei) is both the process of integrating national polities and societies into a supranational framework and the product of integration - European law, institutions, 
policy-making and the emergence of a European identity. Almost all studies on public opinion towards European integration focus on the product of the integration process, trying to explain why citizens think the European Union 'is a good thing', why they trust European institutions, or identify as European citizens. Contrary, I highlight the procedural component of European integration, trying to explain why citizens desire faster or slower integration speed.

Whereas there is a rich literature about the general public opinion on EU issues, especially the general evaluation if citizens think the EU 'is a good thing', we know almost nothing about the desired speed of future integration, the public preferences about the 'European gears'. Are they identical with the general membership evaluation, so that a more positive feeling about the EU translates into a desire for faster integration? Can the economic, political and cultural factors that help explain membership evaluation also explain the desired speed? Do we need new explanatory factors for the temporal phenomenon? My aim in this article is to take stock of these questions.

All theories that explain public attitudes towards European integration offer generalisable hypothesis for the prediction of these attitudes. They gain their explanatory power by a theoretical mechanism that links an individual or national-level characteristic with the realisation of these attitudes. My argument is that until now the scholarly debate was too simplistic about the concept 'support for Ei', especially its temporal dimension. I therefore opt for a distinction of the present support and support for further integration. However, since the standard theoretical accounts are designed in a way that they could explain present and/or future support for integration, my first goal is to disentangle their applicability for the two temporal dimensions.

In a first step, I test the 'better = faster assumption' by taking the most robust economic, political and cultural explanation and assume that they work identically for the explanation of the desired speed than they did previously for the general membership evaluation. The goal of this theory-testing step is twofold. On the side of the independent variables, I describe and explore if the conventional factors work identical for the membership and the speed preferences or if there are differences that could be further theorised. On the side of the dependent variable, I test if the retrospective evaluation of the membership and the prospective desired speed can be equated under the term 'integration preferences' or if a separation between these two dimensions of integration is appropriate. Until now, we do not know if this is the case and it is not trivial either to assume similarity or difference. The analysis on the basis of Eurobarometerdata from 2008 suggests that there are huge differences between the two dependent variables which are also mirrored in the explanatory strength and direction of the independent variables.

As an alternative view, I theorise in a second step about new explanations that account decisively for the temporal component of Ei. In this theory-building step, I develop one explanation based on the retrospective and prospective voting assumption and one explanation that separate the temporal horizons of integration, resulting in a model that takes into account past, present and future evaluations.

The outcomes suppose that this largely neglected aspect of public opinion is on the one hand unique in its explanations of attitudes, since a part of the established explanatory factors for the product evaluation cannot be found significant, and on the other hand, the inclusion of the temporal evaluation is capable of enhancing the quality of the overall explanatory scope for public attitudes toward Ei. 


\section{The temporal implications of European integration}

As Boomgaarden et al. (2011) and Hobolt and de Vries (2016) note on the general state of research about public opinion in the EU, explanatory accounts are very precise about their explanations, but rather general about the phenomenon to be explained, attitudes toward the EU. Earlier studies used the most basic concept of EU support (Duch and Taylor 1997), which is until today present in the literature (Bølstad 2015). Some scholars use an aggregated index of several dimensions of support like membership evaluation, past country benefits of being a member of the Union, the desired speed, and the support for further unification (Hooghe and Marks 2004). These indices stick to the basic assumption that present evaluation and future preferences of the Union can be equated (Hooghe and Marks 2004).

Contrary, Franklin and Wlezien argued already in 1997 that a general positive membership evaluation does not automatically mean that citizens desire more integration. Kopecký and Mudde (2002) develop a similar argument for party positions in Eastern Europe. However, only recently, two authors took upon that findings and acknowledged the general difference between the evaluation of the membership and the future-oriented desire for more integration. Conceptually, Rose (2013) pointed out that satisfaction with the current state of integration does not proof a demand for more integration. Empirically, Hobolt (2014) tested different factors that account for the difference between preferences for 'widening' and 'deepening' of the EU.

In line with Hobolt (2014), I concentrate on citizens' preferences on the dynamic future scenarios of the European project. Compared to stable national political systems, the EU is still a 'polity in the making' (Hooghe and Marks 1999) which is in its temporal nature linear, future oriented, and not cyclical (Goetz and Mayer-Sahling 2009). This procedural nature is the theoretical point of departure for the reasoning about the public opinion towards the integration process. In the aftermath of the failed referendums in France, The Netherlands and Ireland, in addition to the well-known explanatory approaches described below (Eichenberg and Dalton 2007; Hainsworth 2006; Van Klingeren, Boomgaarden, and De Vreese 2013), the temporal component was highlighted in the public discourse. The catchphrase of 'too much too soon' (Eichenberg and Dalton 2007) became prominent as an explanation for the public refusal of further Ei and was spread within the political and academic world. The underlying assumption of the too soon perception is that a process, here European integration, has a certain speed. This speed can be perceived and evaluated by citizens. The data on Ireland show a concrete example how the mix-up of the static and dynamic dimension can lead to wrong conclusions about citizens' preferences for further integration. Whereas it is taken for common knowledge that Irish citizens are very satisfied with EU membership, they still opted against more integration. As Figure 1 shows, the membership evaluation is indeed very stable and positive over time. Contrary, the preferred speed decreases and reaches a negative value the first time in 2006, meaning citizens desired a deceleration of integration. This was materialised in the refusal of the first version of the Lisbon Treaty by referendum. Only after the failed referendum - a deceleration of integration the desired future integration speed increased again.

Table 1 presents the empirical puzzle for the paper. We can see that the relationship between the integration speed preferences and the overall membership evaluation on an individual level is far from linear. Around $45 \%$ of the respondents have linear matching preferences the way that a better evaluation of the EU also translates in a higher desired 


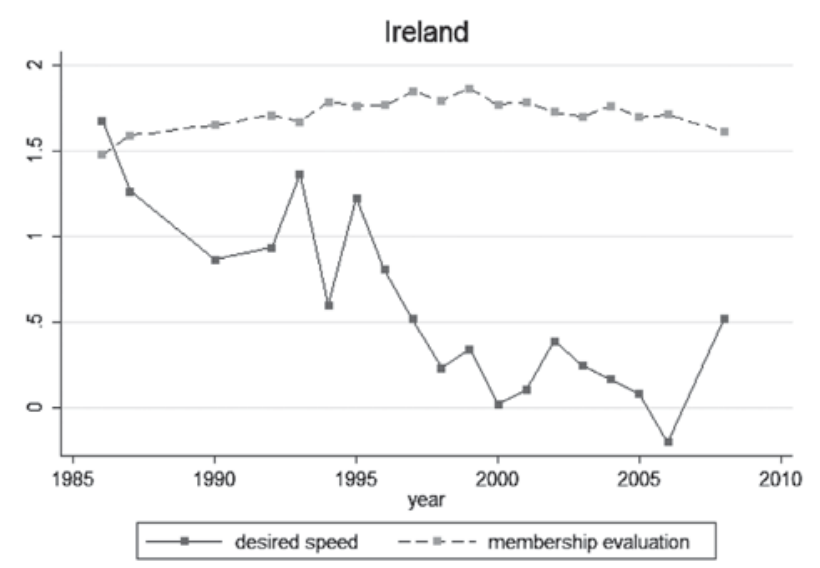

Figure 1. Membership evaluation vs. desired speed for Ireland over time.

Table 1. Relationship between desired speed and membership evaluation for 2008 in $\%(N=22,511)$.

\begin{tabular}{llccccc}
\hline & & \multicolumn{3}{c}{ Desired Speed } & Total \\
\cline { 3 - 6 } & & Slower & Constant & Faster & 14.59 \\
\hline Membership evaluation & Bad & 4.03 & 1.95 & 8.61 & 30.58 \\
& Neutral & 5.62 & 5.18 & 19.78 & 54.83 \\
& Good & 7.78 & 12.99 & 34.06 & 100.00 \\
\hline
\end{tabular}

speed. ${ }^{1}$ However, we can see that around $55 \%$ of respondents do not have this linear relationship of preferences, which leaves room for our explanatory hypotheses to vary between the two dimensions.

\section{Theory: conventional and temporal explanatory variables for public support}

In this section, I review the established theories that connect economic, political and cultural characteristics on the individual and national level with the opinion formation about the European Union (Rohrschneider and Loveless 2011). I take these factors for the explanation of the desired speed of European integration. I do this for the later empirical test if the wellknown membership evaluation and the desired speed of integration can be explained by the same factors. The unproven assumption is that the construct 'support for Ei' is onedimensional and people who generally think positive about European Union membership also desire the integration speed faster as people who dislike the EU, the 'better =faster assumption'. Since all the canonical theories present factors that could explain variance in the support for El (independent from the temporal focus), it seems theoretically justified to conduct this hypothesis building and it seems empirically relevant to investigate the differences and similarities in the explanatory power between these theories. The goal of this article is however not to proof that this assumption holds. Contrary, the surplus of the explorative analysis is to show where discrepancies between the explanation of membership evaluation and desired speed can be found. 
I separate two explanatory levels: (1) individuals with different characteristics are part of (2) nations with different structures, systems and performances. Therefore, two hypotheses per argument are formulated, one for the country level and one for the individual factors.

\section{Economic performance, winners vs. losers and economic perception}

Deduced from liberal trade theory, the main rational assumption states that citizens perceive costs and benefits of the integration process with reference to their position in the economic process (Eichenberg and Dalton 2007). Gabel (1998a) showed that citizens in fact evaluate the $\mathrm{EU}$ on the basis of their personal 'comparative advantage', that is on the basis of their ability to take advantage of the gains from increasing intra- European trade. The so-called winners of integration are assumed to support EU membership as compared to the 'losers'.

Additionally, robust research findings show that citizens' support for Europe is influenced by economic conditions that occur on the national level (Eichenberg and Dalton 1993; Guerra 2013). Especially the affluence of a country has a stable positive effect on EU support because richer nations can gain more through internal market liberalisation. Eichenberg and Dalton $(1993,2007)$ find that higher GDP per capita, less unemployment and a lower inflation rate generate more support for integration.

I hypothesise - on the basis of the 'better = faster assumption' - the same connection between economic measures and the desired speed of integration:

$\mathrm{H} 1 \mathrm{a}$ : The better a country's economic performance, the faster its citizens desired integration speed.

$\mathrm{H} 1 \mathrm{~b}$ : Economic winners of European integration prefer a faster integration speed than losers.

\section{Political performance}

Rational reasoning also explains support for Ei when looking at the performance and the levels of trust people have in certain political institutions and the trade-off created through Ei (Rohrschneider and Loveless 2010). Political trust (Marien and Hooghe 2011) has an effect on EU support. A basic argument is that if national political systems are integrated on a supranational European level, they will transfer sovereignty. This can be interpreted as the 'costs of integration' (Sanchez-Cuenca 2000). According to this 'opportunity cost model' (Christin 2008), the better the performance (or the individual evaluation of the performance) of the national institutions and the worse the performance of the supranational ones, the greater are the opportunity costs for supporting Ei. Citizens who trust their national institutions accordingly evaluate EU membership rather negative. Reframed for the desired speed, the opportunity cost model hypotheses state:

$\mathrm{H} 2 \mathrm{a}$ : The better the institutional performance of the country, the slower is the desired speed of integration.

$\mathrm{H} 2 \mathrm{~b}$ : If a citizen trust national political institutions more than the European ones, he desires a slower speed of integration. 


\section{National identity}

The effects of national identity are most prominently hypothesised and tested by Hooghe and Marks $(2004,2005)$. Exclusive national identity is attributed an effect of defection and preservation against foreign influences like European integration. This negative effect is consistent throughout many studies, partly under the label'Euroscepticism' (McLaren 2002; Sides and Citrin 2007). A more nuanced concept of 'reactive identity' is presented by Vetik, Nimmerfelft, and Taru (2006) and reaches the same conclusion for candidate countries, namely: strong national identity increases the level of Euroscepticism.

I assume analogously that people who interpret European integration as a threat to their national identity opt for a deceleration of integration speed, whereas people who define themselves as European or mainly European should want the integration speed to accelerate:

H3: If a person interprets European integration as a threat to her national identity, she desires a slower speed of Ei.

\section{Temporal considerations}

In a first approximation, two reasons appear that separate the standard EU evaluation from the integration speed that citizens prefer. First, the standard trend variables are retrospective, asking for past EU achievements and country benefits and present evaluations of the situation. In contrast, the speed indicator is prospective, asking for a future preference from a present viewpoint. Ray (2003) notices this difference, stating that there is not only a substantive range difference between these indicators but their outcomes also differ in direction. Citizens clearly distinguish between the satisfaction of the present state of Ei and the desire for further integration. In a broader theoretical frame, proponents of the economic voting approach emphasise the difference between retrospective and prospective voting (Lewis-Beck and Paldam 2000). Since polls are no votes, clearly both backward-looking evaluation about the benefits of the EU membership until the present day and forward-looking preferences about the course of future integration can be formulated and do not necessarily have to match in the direction. The temporal horizon of citizens therefore should make a difference in the explanation of the different EU evaluations.

Previous studies showed the retrospective voting effect on EU support: a positive present evaluation of the economy and the personal financial situation have a positive effect on the present evaluation of the EU. I add a prospective argument for the desired speed accordingly, stating that a positive evaluation of the future situation has a positive effect on the desired speed of integration. The underlying mechanism is the partial connectedness between national and personal economic success with the EU. If a citizen is positive about his economic future, he should desire the realisation of this European future faster compared to a negative-minded citizen.

H4: A better evaluation of the future economic situation leads to a higher desired speed of integration.

My second temporal consideration is the individual satisfaction of European integration as a process in general. The perception and evaluation of this process has a past, a present and a future component with a direction and a speed. I assume a linear and stable connection 
between preferences through time. The past component hereby is the evaluation of the past integration speed. If a citizen has the feeling that the EU evolved too rapidly in the past, a wish for future deceleration seems rational. For the general public opinion, this pattern is theorised in the thermostat theory of Soroka and Wlezien (2010). The public desires a result that converges to the mean. In my case, if past integration was perceived as being too fast, a deceleration should be desired and vice versa.

The present temporal component is one about direction. The EU as a political project that integrates different policy layers into a supranational framework has always the possibility of advancing in several directions. The present general evaluation is if the EU is advancing in the perceived right direction. I hypothesise that citizens who feel that Europe is proceeding in the wrong direction will desire a slower integration speed. The future dimension as last component of my argument hypothesises that the preferences about the prospective advancements of the European project have an effect on its desired speed. My overall hypothesis for the temporal perception combines the three time dimensions:

H5: Affirmation of the past, present, and future development of the EU increases the desired speed of integration.

\section{Data and measurement}

The study comprised of the EU 27 states. On an individual level, I use the second wave of the 2008 Eurobarometer (EB) data-set. ${ }^{2}$

\section{Dependent variable}

For the sake of simplicity and comparability, with most previous studies, only the membership indicator is used in the study as a baseline for the current evaluation. The EB also has an indicator that measures the temporal component of citizen's Ei preferences: the Eurodynamometer. The first half of the question is about the perceived speed of European integration. The question reads as follows:

In your opinion, what is the current speed of building Europe? Please look at these figures.

No.1 is standing still, No.7 is running as fast as possible. Choose the one which best corresponds with your opinion of the current speed of building Europe?

The second part asks about the desired speed:

And which corresponds best to the speed you like?

This item, although in use since 1986, is hardly used as a dependent variable in research studies. ${ }^{3}$

For the use as a dependent variable, I use a simple combination of the current and the desired part of the question. By subtracting the current perceived speed from the desired speed, a net desired speed is calculated. ${ }^{4}$ The net speed has the advantage that it is better comparable between countries with different levels of current perceived speed because the current speed is then used as a baseline that contributes to the desired net speed.

The net speed indicator has 13 possible values ranging from -6 (desired speed $=1$ and current speed $=7$ ) to 6 (desired speed $=7$ and current speed $=1$ ). The negative values 
indicate that respondents want a deceleration of the integration process. The median of 0 is obtained by respondents whose speed preferences equal that of their perception of the current speed, indicating an affirmation of the present integration speed. A positive value is interpreted as a wish for acceleration of the integration process.

\section{Independent variables}

To operationalise the economic dimension of $\mathrm{H} 1$, I use GDP per capita from Eurostat on the country level. On an individual level, I follow the strategy of Gabel (1998a) to use dummy variables for the occupation of respondents. ${ }^{5}$ Economic perception is measured by the egotropic question about the own financial situation and the sociotropic item about the national economic situation. Additionally, I take the level of education as a further operationalisation for the winner/loser dichotomy.

For the political factors, I operationalise the macro-level similar to Sanchez-Cuenca (2000) by the Corruption Perception Index (CPI) and in the robustness test by the World Bank indicator'governmental effectiveness'. Regarding the micro-level attitudes, I use trust in government and trust in the EU as well as their interaction.

As a measure for the cultural component, I rely on the one hand the item that asks if the EU means a loss of cultural identity for obtaining a proxy of the perceived threat for the national identity (Boomgaarden et al. 2011). On the other hand, I include the negative realisation of EU identification, namely that respondents 'do not want to be a European citizen'.

The first of my two novel temporal arguments is the prospective voting connection. According to the evaluation of the present situation, I separate the prospective evaluation in an egotropic and a sociotropic variable. The first asks about the personal financial expectations in 12 months, the second about the national economic expectation for the same horizon. My second temporal hypothesis about the effect of the dynamic perception and evaluation of the EU is split into three dimensions. I operationalise the past procedural evaluation by the EB indicator asking if the past EU building was too fast; for the present dynamic evaluation, I take the question if things in the EU are going in the right or in the wrong direction at the moment. The future component is captured by the indicator if EU building must be pursued or if it has gone too far.

\section{Analysis and results}

My main research interest lies in the explanation of an individual's preferred net speed of Ei. The effects will be estimated by a multi-level approach simultaneously controlling for the effects of macro- and micro-level variables. The model is specified for the present data, resulting in a hierarchical random intercept model.

Starting with only individual factors, Table 2 shows the explanatory effects of the hypothesised factors for the desired net speed and the membership evaluation. ${ }^{6}$ For the general EU support, almost all economic, political and cultural factors show the hypothesised effect (model 2). Economic winners (higher education, better job position) and perceived winners (perception economy and personal situation) of integration are generally in favour of the EU. On a political level, we find contrary to the hypothesised connection that more trust in the national government to an increase of membership support, but the interaction effect 
Table 2. Multi-level results.

\begin{tabular}{|c|c|c|c|c|}
\hline & (1) & $(2)$ & (3) & (4) \\
\hline & Speed & Membership & Speed & Membership \\
\hline Economic situation & $-0.17^{* * *}(0.03)$ & $0.04^{* * *}(0.01)$ & $-0.16^{* * *}(0.03)$ & $0.04^{* * *}(0.01)$ \\
\hline Financial situation & $-0.08^{* * *}(0.03)$ & $0.05^{* * *}(0.01)$ & $-0.07^{* * *}(0.03)$ & $0.05^{* * *}(0.01)$ \\
\hline Education & $0.01 *(0.01)$ & $0.02^{* * *}(0.00)$ & $0.01 *(0.01)$ & $0.02^{* * *}(0.00)$ \\
\hline Self-employed & $0.01(0.07)$ & $0.08^{* * *}(0.02)$ & & \\
\hline House & $0.09(0.08)$ & $0.04 *(0.02)$ & & \\
\hline Manager & $-0.03(0.06)$ & $0.09 * * *(0.02)$ & & \\
\hline White collar & $-0.00(0.06)$ & $0.10^{* * *}(0.02)$ & & \\
\hline Unemployed & $-0.06(0.08)$ & $0.03(0.02)$ & & \\
\hline Student & $-0.01(0.13)$ & $0.05(0.04)$ & & \\
\hline Retired & $0.09(0.06)$ & $0.03^{* *}(0.02)$ & & \\
\hline Trust government & $-0.19 * * *(0.07)$ & $0.08^{* * *}(0.02)$ & $-0.18^{* * *}(0.07)$ & $0.08^{* * *}(0.02)$ \\
\hline Trust EU & $-0.12 * *(0.05)$ & $0.47^{* * *}(0.01)$ & $-0.13^{* * *}(0.05)$ & $0.47^{* * *}(0.01)$ \\
\hline Trust gov*trust EU & $0.15^{*}(0.08)$ & $-0.08^{* * *}(0.02)$ & $0.15^{*}(0.08)$ & $-0.08^{* * *}(0.02)$ \\
\hline Cultural fear & $-0.20^{* * *}(0.05)$ & $-0.21^{* * *}(0.02)$ & $-0.20^{* * *}(0.05)$ & $-0.21^{* * *}(0.02)$ \\
\hline EU identification & $-0.74^{* * *}(0.10)$ & $-0.28^{* * *}(0.03)$ & $-0.74^{* * *}(0.10)$ & $-0.28^{* * *}(0.03)$ \\
\hline Economic expectations & $-0.07^{* *}(0.03)$ & $0.00(0.01)$ & $-0.07^{* *}(0.03)$ & $-0.00(0.01)$ \\
\hline Financial expectations & $0.05^{*}(0.03)$ & $0.04^{* * *}(0.01)$ & $0.05 *(0.03)$ & $0.04^{* * *}(0.01)$ \\
\hline EU past speed & $-0.31^{* * *}(0.02)$ & $-0.05^{* * *}(0.01)$ & $-0.31^{* * *}(0.02)$ & $-0.05^{* * *}(0.01)$ \\
\hline EU present direction & $-0.01(0.02)$ & $0.14^{* * *}(0.01)$ & $-0.01(0.02)$ & $0.14^{* * *}(0.01)$ \\
\hline EU future course & $0.39 * * *(0.02)$ & $0.17^{* * *}(0.01)$ & $0.39 * * *(0.02)$ & $0.17^{* * *}(0.01)$ \\
\hline New EU 12 & $0.43^{* *}(0.20)$ & $-0.14^{* * *}(0.05)$ & $-0.19(0.24)$ & $-0.11 *(0.07)$ \\
\hline GDP per capita & & & $-0.00(0.00)$ & $0.00 *(0.00)$ \\
\hline Corruption perception & & & $-0.19^{* *}(0.08)$ & $-0.02(0.02)$ \\
\hline Constant & $1.74^{* * *}(0.17)$ & $0.77^{* * *}(0.04)$ & $3.41^{* * *}(0.50)$ & $0.82^{* * *}(0.14)$ \\
\hline \multicolumn{5}{|l|}{ Random effects } \\
\hline sd(_cons) & $0.50^{* * *}(0.07)$ & $0.12^{* * *}(0.02)$ & $0.40 * * *(0.06)$ & $0.12^{* * *}(0.01)$ \\
\hline sd(Residual) & $1.90 * * *(0.01)$ & $0.58^{* * *}(0.00)$ & $1.90 * * *(0.01)$ & $0.59 * * *(0.00)$ \\
\hline Observations & 14,096 & 14,604 & 14,096 & 14,604 \\
\hline$A I C$ & $58,246.67$ & $24,522.60$ & $58,230.26$ & $24,563.33$ \\
\hline log likelihood & $-29,096.33$ & $-12,234.30$ & $-29,094.13$ & $-12,260.66$ \\
\hline
\end{tabular}

Note: Standard errors in parentheses.

${ }^{*} p<0.1$; ${ }^{* *} p<0.05$; ${ }^{* *} p<0.01$.

with EU trust is negative. ${ }^{7}$ Thirdly, a strong national cultural identity and the opposition to becoming a European citizen have the assumed negative effects on the evaluation of the EU (H3). Generally, all findings that appear stable in the literature could be reproduced by the model for $2008 .^{8}$

Turning to the desired speed as dependent variable in the first column of Table 2, a different picture occurs: almost all economic and political predictors either changed their level of significance or the direction of the effect. Citizens who think that the current economic and personal financial situation is good desire integration to advance slower than citizens with a bad economic perception. The employment proxies are not significant anymore. Managers, for example, are not different from manual workers in desiring a certain integration speed. In a nutshell, whereas being a winner of integration led to a higher general appreciation of the EU, the effect is non-existent or negative for the future desired speed; hence, hypothesis $1 \mathrm{~b}$ is rejected. Already better situated citizens value the achievements by the EU membership, but desire slower future integration. Economic prosperity is promised through accelerated integration for those who do not have it at the moment.

For the political factors, the assumed cost-benefit mechanism works with reservations. Citizens who trust their national institutions desire slower integration. However, they also desire slower integration when they trust the European level. Hence, the interaction effect 
is rather weak, as can also be seen in the marginal effects of Table A1. Therefore, hypothesis $2 b$ is only partially confirmed.

The cultural indicators are the only ones to realise similar effects for the membership and the speed evaluation. The fear of losing its national culture through El and the refusal of becoming a European citizen cause slower desired speed. This supports $\mathrm{H} 3$ and more generally the assumption of Swidler to see culture as a stable reference frame that serves as 'an ideology which guides people how to change' (Swidler 1986, 282).

My first temporal argument focuses on the prospective voting under individual and societal considerations. I deduced that a positive evaluation of the economic future causes a desire for faster integration speed $(\mathrm{H} 4)$. The empirical results for hypothesis 4 indicate that the prospective voting assumption has to be rejected in favour of a status quo argument. The individual perception of a good economic future for the country leads to a slower desired speed. Citizens evaluate the future under the present circumstances. If they come to a positive evaluation, they want these circumstances - here the state of the integration process - to be held stable. In contrast, citizens who have a negative perception of the future want the integration process to happen faster, an economic'promise of acceleration'. Notably, for the general membership evaluation, the effect has a different direction.

My second temporal explanation that takes the three temporal horizons into account shows differentiated results for the desired speed. The past temporal evaluation causes the hypothesised thermostat effect. A general feeling that the EU grew too fast in the past leads to a desire for deceleration. In contrast, the present evaluation that things are going into the right direction at the moment in the EU has no significant effect on the desired speed of integration. Here, in contrast to the past component, we also see a discrepancy between the effect on the desired speed and the general evaluation. A feeling that everything goes into the right direction at the moment correlates positively with a general positive membership evaluation. Citizens with a positive future evaluation - the third temporal dimension also desire Ei faster, which is in line with $\mathrm{H} 5$ and therefore gets mainly confirmed.

On the country level, I first test if good economic conditions have a positive effect on the public opinion towards the EU (Eichenberg and Dalton 1993). ${ }^{9}$ I can reproduce this pattern for the membership indicator in column 4 of Table 2. Contrary, higher GDP per capita decreases the desired speed (model 3), however not statistically significant. The results indicate that people from countries who are economically better suited ascribe past integration a certain responsibility for this situation and hence value the past achievement. However, they do not want integration to be faster since they already gained; $\mathrm{H} 1 \mathrm{a}$ has to be rejected.

Second, on the political institutional level, I could reproduce the findings of Sanchez-Cuenca (2000). The CPI has a negative impact on the desired speed of integration, meaning that the better the national institutions, the slower citizens' desire for integration speed, most likely because they fear a decline of the quality through $\mathrm{Ei}$. $\mathrm{H} 2 \mathrm{a}$ receives support. The overall evaluation of the $\mathrm{EU}$, in contrast, is not significantly related to the political performance. This is again evidence for the tendency that the future of Europe is more evaluated under a political than an economic frame, whereas the past achievements measured through the overall evaluation can best be explained by economic factors. ${ }^{10}$

A further insight into the drivers for the effects delivers the dummy if a citizen is from the old EU 15 states or the newer central and eastern European states. First, there are previous valuable studies that generally detect a difference between these two groups in terms of EU support (Garry and Tilley 2007). And indeed, in model 1 of Table 2, the 'new member' 
dummy is positive and significant, meaning that the citizens of the newer member states generally desire faster integration (in contrast to the overall evaluation in model 2 which is generally better in the old member states). However, this effect diminishes when introducing the contextual effects, meaning that the concrete political performance of a system explains the difference and not its genuine time of accession. A second hint that there are fewer differences between old and new member states (and eventually other country clusters) is delivered by our robustness check in Table A2 models 3 and 4 . Here, I rerun the models only for the old member states. The results of almost all indicators stay surprisingly stable, so the results are not dependent on one specific accession cohort.

Generally, my analysis suggests a difference in the explanation of the overall membership evaluation and the desired speed of future integration. For the membership evaluation, Gabel's classic claim that'citizens base their utilitarian evaluation on the welfare they derive from economic integration' (1998b, 37) is still true. The better the personal and country situation on the economic dimension, the better the EU membership evaluation. Contrary, my main result shows that citizens with the same (good) economic conditions do not desire the speed of future integration to be faster. Rather, they opt for a deceleration of integration. I interpret this finding as the economic 'promise of acceleration', namely that momentary economic 'losers' still see European integration as a means to increase their well-being. For the political dimension, this trend can also be seen. Bad institutional performance leads to a desired acceleration of integration.

\section{Conclusion}

My aim was twofold. On an explorative stage, I asked if the overall support for EU membership can be equalised with the desire for future integration speed. I found hardly any evidence for the support of this assumption. Better evaluation does not automatically translate into faster desired speed. This finding questions first the general equation of present membership evaluation and willingness for future support which can be seen in many studies and policy papers. For example, Bølstad (2015) states that in his analysis, public opinion precedes integration, and predicts a considerable portion of the variance in integration over time. He thereby relies however solely on the membership indicator. As I prove here, this indicator does not mirror preferences for further integration; therefore, his conclusion might be superficial. Second, it also raises doubts to the use of indices which combine the membership and the desired speed indicator for grasping general support (Hooghe and Marks 2004).

My second goal was to show which factors can explain our new dependent variable: desired speed. I showed that this procedural aspect is really to a large extent interpreted and evaluated independently from the overall support for the EU. I find that people who are satisfied with the present state of the EU or have attributes that are positively correlated with a positive EU image rather want stability than change in the integration process. Generally, economic conditions and perceptions work better for explaining overall membership than desired speed. Selected significant findings in my analysis suggest that citizens with a better economic endowment desire integration to happen slower. Since the costs and benefits of future integration are uncertain, rational theories on the basis of these calculations are not suited to explain support for future integration. This again suggests that one should not equate membership evaluation and preferences for future integration. For example, the findings of Eichenberg and Dalton (2007) or Gabel (1998a) cannot be used to 
infer that economic well-being leads to a preference for faster integration. I interpret this as the 'promise of acceleration' for citizens who are on the economic downside at the moment. For these citizens, fast Ei comes with the promise of an improvement of the present situation in the future. The same holds for political factors like the perception of corruption or the satisfaction with the present state of integration. The better they are, the slower citizens' desire for future integration. The only dimension which is stable between membership evaluation and desired speed is the cultural one. Cultural fear related to the loss of national identity through $\mathrm{Ei}$ is a good predictor for disliking general membership and desiring slower speed of Ei.

Conceptually, the European polity is, compared to national political systems, a unique object of investigation because part of its nature is its dynamic development. The preferences for the integration speed come as a by-product of the EU's uniqueness. Citizens recognise this dynamic component when asked for their feelings and preferences about the EU. The simple equation 'better $=$ faster' does not hold. This has concrete implications for the policy-makers of the Ei course. The design of the procedural component of Ei is a phenomenon that should be synchronised with the public opinion towards it. The schedule or roadmap of integration seems to be determined by the current possibilities in the windows of opportunity of integration. The spirit of 'if we don't do it now, we'll never make it' might not always be appropriate for Ei. To procrastinate certain steps for a while should not necessarily communicate that these steps will never be completed. Rather, the progress of the EU should be something that can be slower than necessary without being interpreted as a failure or an elimination of some integration steps.

\section{Notes}

1. This is in line with the finding from Hooghe and Marks 2004 who find a correlation of 0.409 in their analysis of the data from 2000.

2. This is due to the fact that this wave is the latest that contains all relevant indicators for this study, especially the speed indicator.

3. There are six notable researchers and research groups using the indicator as well: SanchezCuenca (2000) uses it as a proxy for general attitudes towards Ei, Ray (2003) includes the speed dimension as a robustness check for the unification indicator, Hooghe and Marks (2004) incorporate the Eurodynamometer in their index of overall public opinion on the EU, Brinegar et al. (2004) use it as the dependent variable for a test of the 'varieties of capitalism' hypothesis and Vetik et al. use a somehow related indicator asking if candidate countries should join the EU 'as soon as possible'. However, none of these studies is really interested in integration speed; they have rather technical reasons to use this indicator as a representation for the general evaluation of the EU. Recently, Boomgaarden et al. (2011) include the dynamometer as one item of their more encompassing 'strengthening' dimension. Additionally, Hobolt and de Vries (2016) take parts of the speed indicator in their overview article under the surprising label 'policy support'.

4. Following the general distinction of political psychology, it can be said that the current perceived speed is the cognitive component, the desired speed is the affective component and the net desired speed is the evaluative component of the integration speed.

5. The category left out for comparison was'manual worker'. So the effects of all other occupations are seen in comparison to this category.

6. A note on the technical aspect: the speed indicator has the parameter values from -6 to 6 , therefore the OLS conditions are fulfilled. The membership indicator has only three realisations, $-1,0,1$. Therefore, we applied an ordered logit model. Checking this against the OLS multi-level outcomes, it appeared that there were no significant differences. So, since the interest is not on the effect size but only on the direction of the effects, we finally use for both dependent 
variables OLS models since they are easier to compare. As a robustness check, I transformed the speed indicator into a variable with three realisations as the membership measure. Generally, the results stay robust and the model fits converge.

7. Table $\mathrm{A} 1$ of the appendix contains the average marginal effects for the interaction of both trust levels. Trust in national government in addition to trust in the EU lowers the membership evaluation significantly, whereas this value is insignificant for the desired speed.

8. Three control variables are included in every model; however, due to space constraints, they are not included in the results tables. They are: respondents' age, gender and left-right placement.

9. To check the robustness of the results, a reduced model of individual-level factors is used. My selection criterion was to include all individual predictors that reached significance for the desired net speed.

10. Since the CPI is based on individual evaluation of the political performance of a country, we additionally test the robustness of my results in models 1 and 2 of Table A2. We can see that the variable governmental effectiveness as a concrete measure of political institutional performance from the World Bank indicators has the same effect.

\section{Disclosure statement}

No potential conflict of interest was reported by the author.

\section{Funding}

This work was supported by the Center of Excellence Cultural Foundations of Social Integration.

\section{References}

Bølstad, J. 2015. “Dynamics of European Integration: Public Opinion in the Core and Periphery." European Union Politics 16 (1): 23-44.

Boomgaarden, H. G., A. R. Schuck, M. Elenbaas, and C. H. de Vreese. 2011. "Mapping EU Attitudes. Conceptual and Empirical Dimensions of Euroscepticism and EU Support." European Union Politics 12: 241-266.

Brinegar, A., S. Jolly, and H. Kitschelt. 2004. "Varieties of Capitalism and Political Divides Over European Integration." In European Integration and Political Conflict, edited by G. Marks and M. R. Steenbergen, 62-89, Cambridge: Cambridge University Press.

Christin, T. 2008."Political- and Identity-based Support for European Integration. An Analysis of Member States and Candidate Countries." Diss., University of St. Gallen.

Duch, R., and M. Taylor. 1997. "Economics and the Vulnerability of the Pan-European Institutions." Political Behavior 19: 65-80.

Eichenberg, R., and R. Dalton. 1993. “Europeans and the European Community: The Dynamics of Public Support for European Integration." International Organization 47 (4): 507-534.

Eichenberg, R., and R. Dalton. 2007. "Post-Maastricht Blues. The Transformation of Citizen Support for European Integration, 1973-2004." Acta Politica 42: 128-152.

Gabel, M. 1998a. "Public Support for European Integration. An Empirical Test of Five Theories." The Journal of Politics 60 (2): 333-354.

Gabel, M. 1998b. Interests and Integration. Ann Arbor: University of Michigan Press.

Garry, J., and J. Tilley. 2007. "Public Support for Integration in the Newly Enlarged EU: Exploring Differences between Former Communist Countries and Established Member States." In European Elections Aftern Eastern Enlargement. Preliminary Results from the European Election, edited by M. Marsh, S. Mikhaylov and H. Schmitt, 181-203. Mannheim: MZES.

Goetz, K. H., and J.-H. Mayer-Sahling. 2009. "Political Time in the EU: Dimensions, Perspectives, Theories.” Journal of European Public Policy 16: 180-201.

Guerra, S. 2013. Central and Eastern European Attitudes in the Face of Union. Houndmills: Palgrave Macmillan. 
Hacking, I. 1999. The Social Construction of What? Harvard: Harvard University Press.

Hainsworth, P. 2006. "France Says No. the 29 May 2005 Referendum on the European Constitution." Parliamentary Affairs 59: 98-117.

Hobolt, S. B. 2014. "Ever Closer or Ever Wider? Public Attitudes towards Further Enlargement and Integration in the European Union." Journal of European Public Policy 21 (5): 664-680.

Hobolt, S. B., and C. E. de Vries. 2016. "Public Support for European Integration." Annual Review of Political Science 19: 413-432.

Hooghe, L., and G. Marks. 1999. "The Making of a Polity. The Struggle over European Integration." In Continuity and Change in Contemporary Capitalism, edited by H. Kitschelt, 70-97. Cambridge: Cambridge University Press.

Hooghe, L., and G. Marks. 2004. "Does Identity or Economic Rationality Drive Public Opinion on European Integration?" PS: Political Science and Politics 37 (03): 415-420.

Hooghe, L., and G. Marks. 2005. "Calculation, Community and Cues." European Union Politics 6 (4): 419-443.

Kopecký, P., and C. Mudde. 2002. "The Two Sides of Euroscepticism. Party Positions on European Integration in East Central Europe." European Union Politics 3 (3): 297-326.

Lewis-Beck, M., and M. Paldam. 2000. "Economic Voting. An Introduction." Electoral Studies 19: 113-121.

Marien, S., and M. Hooghe. 2011. "Does Political Trust Matter? An Empirical Investigation into the Relation between Political Trust and Support for Law Compliance." European Journal of Political Research 50 (2): 267-291.

McLaren, L. 2002. “Public Support for the European Union. Cost/Benefit Analysis or Perceived Cultural Threat." The Journal of Politics 64: 551-556.

Ray, L. 2003. "Reconsidering the Link between Incumbent Support and Pro-EU Opinion." European Union Politics 4 (3): 259-279.

Rohrschneider, R., and M. Loveless. 2010. "Macro Salience. How Economic and Political Contexts Mediate Popular Evaluations of the Democracy Deficit in the European Union." Journal of Politics 72: 1029-1045.

Rohrschneider, R., and M. Loveless. 2011. "Public Perceptions of the EU as a System of Governance." Living Reviews in European Governance (LREG) 6 (2): 5-38.

Rose, R. 2013. Representing Europeans: A Pragmatic Approach. Oxford: Oxford University Press.

Sanchez-Cuenca, I. 2000. "The Political Basis of Support for European Integration." European Union Politics 1: 147-171.

Sides, J., and J. Citrin. 2007. "European Opinion about Immigration. The Role of Identities, Interests and Information." British Journal of Political Science 37 (03): 477-504.

Soroka, S. N., and C. Wlezien. 2010. Degrees of Democracy: Politics, Public Opinion, and Policy. Cambridge: Cambridge University Press.

Swidler, A. 1986. "Culture in Action. Symbols and Strategies." American Sociological Review 51 (2): 273-286.

Van Klingeren, M., H. J. Boomgaarden, and C. H. De Vreese. 2013. “Going Soft or Staying Soft: Have Identity Factors Become More Important than Economic Rationale When Explaining Euroscepticism?" Journal of European Integration 35 (6): 689-704.

Vetik, R., G. Nimmerfelft, and M. Taru. 2006. "Reactive Identity versus EU Integration.” JCMS: Journal of Common Market Studies 44 (5): 1079-1102. 


\section{Appendix 1}

Table A1. Average marginal effects for trust in government when trust in EU is present.

\begin{tabular}{lcc}
\hline & Speed & Membership \\
& $\mathrm{d} y / \mathrm{d} x$ & $\mathrm{~d} y / \mathrm{d} x$ \\
\hline Trust gov $=0$ & $-0.11^{* *}(0.05)$ & $0.48^{* * *}(0.01)$ \\
Trust gov $=1$ & $0.02(0.06)$ & $0.39^{* * *}(0.02)$ \\
\hline
\end{tabular}

Table A2. Multi level results: robustness checks: new contextual variables (Model 1-2) and separation of membership cohorts (Model 3-4).

\begin{tabular}{|c|c|c|c|c|}
\hline & (1) & $(2)$ & (3) & (4) \\
\hline & Speed & Membership & Speed old 15 & Membership old 15 \\
\hline Economic situation & $-0.16^{* * *}(0.03)$ & $0.04^{* * *}(0.01)$ & $-0.17^{* * *}(0.03)$ & $0.01(0.01)$ \\
\hline Financial situation & $-0.06^{* * *}(0.02)$ & $0.06^{* * *}(0.01)$ & $-0.05^{*}(0.03)$ & $0.06^{* * *}(0.01)$ \\
\hline Trust government & $-0.19^{* * *}(0.06)$ & $0.09^{* * *}(0.02)$ & $-0.22^{* * *}(0.07)$ & $0.12^{* * *}(0.02)$ \\
\hline Trust EU & $-0.11^{* *}(0.05)$ & $0.48^{* * *}(0.01)$ & $-0.08(0.06)$ & $0.51^{* * *}(0.02)$ \\
\hline Trust gov*trust EU & $0.14^{*}(0.07)$ & $-0.09^{* * *}(0.02)$ & $0.14(0.09)$ & $-0.14^{* * *}(0.03)$ \\
\hline Cultural fear & $-0.20^{* * *}(0.05)$ & $-0.21^{* * *}(0.01)$ & $-0.23^{* * *}(0.06)$ & $-0.21^{* * *}(0.02)$ \\
\hline EU identification & $-0.72^{* * *}(0.10)$ & $-0.29 * * *(0.03)$ & $-0.77^{* * *}(0.11)$ & $-0.31^{* * *}(0.03)$ \\
\hline Economic expectations & $-0.06^{* * *}(0.02)$ & $-0.00(0.01)$ & $-0.05(0.03)$ & $-0.02^{* *}(0.01)$ \\
\hline Financial expectations & $0.05^{*}(0.03)$ & $0.04^{* * *}(0.01)$ & $0.08^{* *}(0.03)$ & $0.04^{* * *}(0.01)$ \\
\hline EU past speed & $-0.32^{* * *}(0.02)$ & $-0.05^{* * *}(0.01)$ & $-0.39^{* * *}(0.03)$ & $-0.04^{* * *}(0.01)$ \\
\hline EU present direction & $-0.01(0.02)$ & $0.14^{* * *}(0.01)$ & $0.02(0.03)$ & $0.14^{* * *}(0.01)$ \\
\hline EU future course & $0.37^{* * *}(0.02)$ & $0.17^{* * *}(0.01)$ & $0.37^{* * *}(0.03)$ & $0.18^{* * *}(0.01)$ \\
\hline Age & $-0.04 * * *(0.01)$ & $-0.01^{* *}(0.00)$ & $-0.03^{* * *}(0.01)$ & $-0.01^{* *}(0.00)$ \\
\hline Left-right & $-0.01^{* * *}(0.00)$ & $0.00 * *(0.00)$ & $-0.01^{* * *}(0.00)$ & $0.00(0.00)$ \\
\hline New EU 12 & $0.20(0.21)$ & $-0.15^{* * *}(0.05)$ & & \\
\hline Effectiveness & $-0.36^{* *}(0.17)$ & $-0.02(0.04)$ & & \\
\hline GDP per capita & & & $-0.00(0.00)$ & $0.00 *(0.00)$ \\
\hline Corruption perception & & & $-0.21^{* *}(0.09)$ & $-0.01(0.02)$ \\
\hline Constant & $2.33^{* * *}(0.28)$ & $0.95^{* * *}(0.07)$ & $3.73^{* * * *}(0.57)$ & $0.90^{* * *}(0.16)$ \\
\hline \multicolumn{5}{|l|}{ Random-effects } \\
\hline sd(_cons) & $0.45^{* * *}(0.06)$ & $0.12^{* * *}(0.01)$ & $0.39^{* * *}(0.07)$ & $0.13^{* * *}(0.02)$ \\
\hline sd(Residual) & $1.89^{* * *}(0.01)$ & $0.59^{* * *}(0.00)$ & $1.94^{* * *}(0.01)$ & $0.06^{* * *}(0.00)$ \\
\hline Observations & 15,096 & 15,632 & 9809 & 10,083 \\
\hline$A / C$ & $62,192.08$ & $26,229.94$ & $40,861.11$ & $17,352.70$ \\
\hline log likelihood & $-31,077.04$ & $-13,095.97$ & $-20,411.55$ & -8657.35 \\
\hline
\end{tabular}

Note: Standard errors in parentheses.

${ }^{*} p<0.1$; ${ }^{* *} p<0.05$; ${ }^{* *} p<0.01$. 